\title{
Comparative clinical study of pulsatile and non-pulsatile perfusion in 350 consecutive patients
}

\author{
KM TAYLOR, WH BAIN, KG DAVIDSON, MA TURNER \\ From the University Department of Cardiac Surgery, Royal Infirmary, Glasgow
}

ABSTRACT Pulsatile perfusion has been shown to offer significant haemodynamic advantages over non-pulsatile perfusion in many experimental studies. Clinical acceptance of pulsatile perfusion during cardiac surgical procedures has, however, been hampered by the lack of technologically satisfactory pulsatile pump systems, and by inadequate clinical experience of routine use of pulsatile perfusion. The recent introduction of reliable pulsatile pump systems with low haemolysis characteristics has made possible the clinical validation of the previous experimental studies. We describe the results of a prospective study of mortality, haemodynamic morbidity, and haematological status, in 350 consecutive adult patients submitted to cardiopulmonary bypass procedures in a surgical unit over a 12-month period. One hundred and seventy five patients were perfused with conventional non-pulsatile flow and 175 with pulsatile flow, using a modified roller-pump pulsatile system (Cobe-Stockert). The groups were closely similar in terms of preoperative characteristics, referral category, and pathology requiring surgery. Operative techniques, bypass parameters, and anaesthetic regime were standardised in both groups. The results were as follows. (1) Total mortality was significantly lower in the pulsatile group (4.6\%) compared with the non-pulsatile group $(10.3 \%), p=0.06$. (2) The incidence of deaths attributable to post-perfusion low cardiac output was significantly lower in the pulsatile group (1.1\% compared with 6.3\%, p =0.02). (3) Requirement for mechanical (intra-aortic balloon) or drug circulatory support was significantly lower in the pulsatile group. (4) The use of pulsatile perfusion was not associated with any increase in haemolysis, blood cell depletion, or postoperative bleeding problems.

Interest in the clinical applicability of pulsatile perfusion has recently been reawakened, both as a result of the development of reliable, commercially available pump systems and in view of recent clinical research defining more clearly the pathophysiological effects of non-pulsatile perfusion.

A prospective clinical study was designed to investigate the clinical applicability of routine pulsatile flow during open-heart procedures, with particular emphasis on the comparative effects of pulsatile and non-pulsatile perfusion on haemodynamic morbidity and mortality statistics. The following specific aims were included in the study.

1 To use pulsatile cardiopulmonary bypass with the Cobe-Stockert system-a modified roller-pump system previously studied by the authors in relation to the metabolic and haemodynamic effects of pulsatile flow, ${ }^{1-4}$ and assess its clinical applicability in

Address for reprint requests: Mr Kenneth M Taylor, University Department of Cardiac Surgery, Royal Infirmary, Glasgow G4 OSF. terms of reliability, choice of circuits and cannulae, haemolysis index, and the production of acceptable pulsatile arterial flow.

2 To document significant haemodynamic parameters in a large series of patients, perfused with pulsatile or non-pulsatile flow, detailing and comparing mortality, incidence of low cardiac output state, use of intra-aortic balloon pump, and use of inotrope therapy in the postoperative period.

\section{Patients and methods}

Three hundred and fifty consecutive patients admitted to the cardiac surgical unit in Glasgow Royal Infirmary from 1 April 1978 to 31 March 1979 were included in the study. Informed patient consent and ethical committee approval were obtained before starting the study. All patients had cardiac procedures performed under cardiopulmonary bypass. These 350 patients represented the total bypass surgical patients operated on in the one unit in that 
12-month period. No patients were excluded from the study total, which comprised urgent and emergency cases in addition to elective procedures. Patients were allocated arbitrarily to pulsatile or non-pulsatile perfusion and there were 175 patients in each group. The patients were operated on by one of four consultant cardiac surgeons, each surgeon operating on the same number of patients in the two groups (table 1).

The patients were assessed in terms of preoperative characteristics (table 2), referral category (table 3), and underlying pathology requiring surgery (table 4). There were no significant differences between the groups in any of these parameters.

All operative procedures were carried out under a standard protocol encompassing anaesthesia, bypass circuitry, oxygenator, prime composition, and immediate postoperative care programme. Anaes-

Table 1 Distribution of patients according to consultant surgeon involved

\begin{tabular}{lcc}
\hline Surgeon & Pulsatile group & Non-pulsatile group \\
\hline A & 55 & 55 \\
B & 43 & 43 \\
C & 41 & 41 \\
D & 36 & 36 \\
Total & 175 & 175 \\
\hline
\end{tabular}

Table 2 Preoperative characteristics (mean $\pm S D$ )

\begin{tabular}{lcc}
\hline Parameter & Pulsatile group & $\begin{array}{l}\text { Non-pulsatile } \\
\text { group }\end{array}$ \\
\hline Number of patients & 175 & 175 \\
Age (years) & $48.42 \pm 10.95$ & $46.59 \pm 12.53$ \\
Weight (kilos) & $64.81 \pm 11.34$ & $64.78 \pm 12.00$ \\
Body surface area $\left(\mathrm{m}^{2}\right)$ & $1.71 \pm 0.18$ & $1.69 \pm 0.22$ \\
Previous cardiac surgery & $31(17.7 \%)$ & $26(14.9 \%)$ \\
\hline
\end{tabular}

Table 3 Referral categories

\begin{tabular}{lrr}
\hline & Pulsatile group & Non-pulsatile group \\
\hline Elective & $154(88 \%)$ & $155(88.6 \%)$ \\
Urgent & $13(7.4 \%)$ & $11(6.3 \%)$ \\
Emergency & $8(4.6 \%)$ & $9(5 \cdot 1 \%)$ \\
Total & 175 & 175 \\
\hline
\end{tabular}

Table 4 Pathology requiring surgery

\begin{tabular}{|c|c|c|}
\hline Pathology & Pulsatile group & $\begin{array}{l}\text { Non-pulsatile } \\
\text { group }\end{array}$ \\
\hline $\begin{array}{l}\text { Valve disease } \\
\text { Coronary disease } \\
\text { Valve and coronary disease } \\
\text { Congenital } \\
\text { Miscellaneous } \\
\text { Total }\end{array}$ & 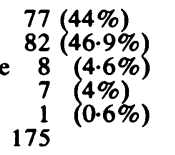 & $\begin{array}{rr}66 & (37.7 \%) \\
86 & (49.1 \%) \\
10 & (5.7 \%) \\
10 & 5.7 \%) \\
3 & (1.7 \%) \\
175 & \end{array}$ \\
\hline
\end{tabular}

thesia was induced with sodium pentothal and maintained with nitrous oxide, oxygen, and intravenous morphine. The total morphine dosage administered during the operation was $<0.2 \mathrm{mg} / \mathrm{kg}$ body weight/patient for both groups. Intermittent positive pressure ventilation was maintained throughout operation (except for the bypass period) and for the first 15-20 hours after operation.

Though there were more valve patients in the pulsatile group and more coronary patients in the nonpulsatile group, these differences were not significant. Within the valve surgery patients, the pulsatile group had 102 valves replaced (equivalent to 1.32 valves per patient) compared with 70 valves in the non-pulsatile group (1.06 valves per patient). This difference is significant but would bias results in favour of the non-pulsatile group.

Within the coronary disease patients, the pulsatile group had 1.8 coronary artery grafts per patient compared to 1.96 grafts per patient in the nonpulsatile group, but this difference is not significant. There were 20 patients in both pulsatile and nonpulsatile groups who required left ventricular aneurysm resection in addition to coronary artery bypass grafting. There were eight $(4.6 \%)$ pulsatile patients who required valve replacement plus coronary artery grafting, compared with $10(5.7 \%)$ nonpulsatile patients.

\section{CARDIOPULMONARY BYPASS PROTOCOL}

Conventional atrio-aortic bypass was used in all cases, using a Temptrol bubble oxygenator. The extra-corporeal circuit was set up as follows:

Venous cannulae-two right-angled Polystan or straight whistle-tip cannulae, joined via a Y-piece to a $1 / 2$ " venous line.

Tubing in pump race-1/2" diameter.

Arterial line filter-a $40 \mu$ screen filter (Ultipor) was inserted in the arterial line in each case.

Arterial cannula-Sarns "hook" type cannula or USCI cannula of 18-22 gauge, inserted into the ascending aorta, and connected to a $3 / 8$ " arterial line.

The Cobe-Stockert pump system was used in all cases with pulsatile and non-pulsatile perfusion being used acording to the following protocol: in the non-pulsatile group the pump was used in the nonpulsatile mode throughout the perfusion. In the pulsatile group bypass was started in the non-pulsatile mode, and switched to pulsatile flow when left ventricular ejection stopped. Pulsatile perfusion was maintained until left ventricular ejection was restored, when the pump was switched back to the non-pulsatile mode. Pulsatile flow controls were set to provide a rate of $70-72$ beats/minute, with a pump run-time of $50-55 \%$ of the total cycle length. 
Pulse pressures $>25-30 \mathrm{mmHg}$ were consistently achieved (figure). Synchronised counterpulsation was not used in any patient in the pulsatile group. Perfusion pressures in the pulsatile group were mean peak systolic pressure $=74.3 \mathrm{mmHg} \pm$ $1 \cdot 1 \mathrm{SEM}$ and mean diastolic pressure $=42.2 \mathrm{mmHg}$ \pm 0.7 SEM.

Myocardial protection during aortic crossclamping was accomplished by topical hypothermia alone in approximately $95 \%$ of the patients in both groups and topical hypothermia plus aortic rootflush cardioplegia in the remainder. The extracorporeal circuit was primed with $2-2.5$ litres of Ringer's lactate solution to which was added $1 \mathrm{~g}$ Mannitol and $100 \mathrm{mmol} 8.4 \%$ sodium bicarbonate. The maintained pump flow rate was calculated according to the formula mean flow $=2.41 / \mathrm{m}^{2} / \mathrm{min}$. Total bypass was maintained during the operative procedures.

The principal operative parameters are shown in table 5 . The total bypass and aortic cross-clamp times are longer in the pulsatile group, probably reflecting the greater number of valve replacements performed in this group. There were no other significant differences between the groups in terms of mean pump flow, mean perfusion pressure, haematocrit, or core temperature on bypass.

All patients were studied prospectively and mortality and morbidity statistics documented for each group. Statistical analysis of the results were carried out using Student's $t$ test and Fisher's exact test for a $2 \times 2$ table.

\section{Results}

MORTALITY STATISTICS (TABLE 6)

Only deaths occurring within one month of the day of operation were included in the results. There were eight deaths in the pulsatile group (4.6\%) compared with 18 deaths in the non-pulsatile group $(10.3 \%), p=0.06$. Mortality statistics for each group according to referral category showed a mortality for elective cases of $3.25 \%$ for the pulsatile group, compared with $8.4 \%$ for the non-pulsatile group. The \% mortality was also lower in the pulsatile group for urgent and emergency categories, but these differences did not achieve significance.

\section{HAEMODYNAMIC MORBIDITY (TABLE 7)}

The clinical results were considered in detail in order to document the haemodynamic status of the patients in each group.

\section{Incidence of intraoperative deaths}

In the pulsatile group, there was one death during operation, the patient being unable to be weaned off bypass. This represents a mortality of $0.6 \%$ of all cases, compared with seven deaths $(4 \%)$ in the non-pulsatile group, $\mathrm{p}=0.07$.

Incidence of deaths attributed to low cardiac output occurring within 24 hours of surgery

These figures were determined by adding to the intraoperative deaths those patients who survived the operation but died within the first 24 hours as a result of a low cardiac output state. This gave a total of two patients $(1.1 \%)$ in this category in the pulsatile group, compared with 11 patients $(6.3 \%)$ in the non-pulsatile group, $p=0.02$.

Use of intra-aortic balloon pump (IABP) to wean patients off bypass

Mechanical circulatory support with an IABP was used in one patient in the pulsatile group $(0.6 \%)$ compared with seven patients in the non-pulsatile group (4.0\%), $p=0.07$. The decision to insert the IABP was taken by the surgeon involved in the par-
Arterial blood pressure

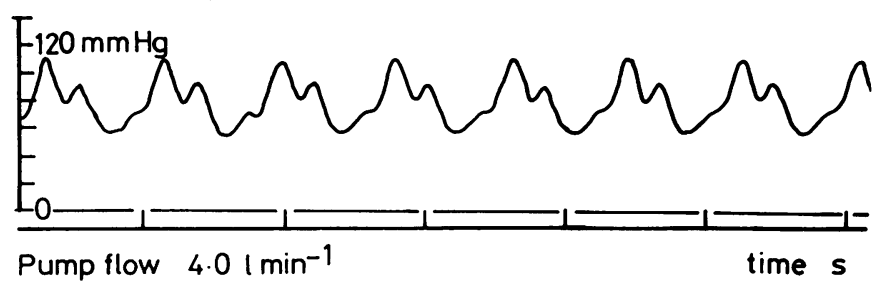

Figure Radial artery wave-form in patient on total cardiopulmonary bypass with pump set in the pulsatile mode. Trigger rate 70 beats/min; pump run time $55 \%$ of total cardiac cycle length. 
Table 5 Cardiopulmonary bypass data (mean $\pm S E M)$

\begin{tabular}{llc}
\hline & Pulsatile group & Non-pulsatile group \\
\hline Total bypass time (min) & $92 \cdot 17 \pm 2 \cdot 82$ & $84 \cdot 88 \pm 3 \cdot 19$ \\
Cross-clamp time (min) & $46.95 \pm 1 \cdot 8$ & $38 \cdot 44 \pm 1 \cdot 54$ \\
Mean pump flow (l/min) & $3 \cdot 32 \pm 0 \cdot 03$ & $3 \cdot 22 \pm 0 \cdot 03$ \\
Mean perfusion pressure (mmHg) & $49 \cdot 83 \pm 1 \cdot 0$ & $50 \cdot 09 \pm 0 \cdot 87$ \\
Mid-bypass haematocrit (\%) & $23 \cdot 56 \pm 0 \cdot 24$ & $23 \cdot 53 \pm 0 \cdot 25$ \\
Core temperature on bypass $\left({ }^{\circ} \mathrm{C}\right)$ & $30 \cdot 8 \pm 0 \cdot 4$ & $30 \cdot 6 \pm 0 \cdot 6$ \\
Myocardial protection & & 94 \\
Topical hypothermia (\% of cases) & 95 & 6 \\
Topical hypothermia (\% of cases) and root flush cardioplegia & 5 & \\
\end{tabular}

Conversion: traditional to SI units-1 $\mathrm{mm} \mathrm{Hg}=0 \cdot 13 \mathrm{kPa}$.

Table 6 Mortality statistics

\begin{tabular}{llcl}
\hline & $\begin{array}{l}\text { Pulsatile } \\
\text { group }\end{array}$ & $\begin{array}{l}\text { Non-pulsatile } \\
\text { group }\end{array}$ & $p$ \\
\hline $\begin{array}{l}\text { Number of cases } \\
\text { Total deaths }\end{array}$ & $\begin{array}{c}175 \\
8(4.6 \%)\end{array}$ & $\begin{array}{c}175 \\
18(10.3 \%)\end{array}$ & 0.06 \\
$\begin{array}{l}\text { \%ortality } \\
\text { Elective cases }\end{array}$ & $3.2 \%$ & $8.4 \%$ & NS \\
$\begin{array}{l}\text { Urgent cases } \\
\text { Emergency cases }\end{array}$ & $15.4 \%$ & $27.2 \%$ & NS \\
\hline
\end{tabular}

Table 7 Haemodynamic morbidity

\begin{tabular}{llll}
\hline & $\begin{array}{l}\text { Pulsatile } \\
\text { group }\end{array}$ & $\begin{array}{l}\text { Non-pulsatile } \\
\text { group }\end{array}$ & $p$ \\
\hline Total deaths & $\mathbf{8}(4 \cdot 6 \%)$ & $18(10 \cdot 3 \%)$ & 0.06 \\
$\begin{array}{l}\text { Intraoperative deaths } \\
\text { Total low output deaths } 2(0.6 \%)\end{array}$ & $7(4 \%)$ & $0 \cdot 07$ \\
$\begin{array}{l}\text { Use of IABP } \\
\begin{array}{l}\text { Use of inotropic } \\
\text { infusion }\end{array}\end{array}$ & $1(0.6 \%)$ & $11(6.3 \%)$ & $0 \cdot 02$ \\
& $7(4.0 \%)$ & $19(10.9 \%)$ & 0.07 \\
\hline
\end{tabular}

ticular case, but the facility for IABP support was available for all patients in the study.

Use of inotropic drug infusion in the first 24 hours after surgery

Adrenalin was the first choice inotropic drug used by all four surgeons during the study period. Adrenalin infusion was used to counteract low cardiac output in seven cases in the pulsatile group (4.0\%) and in the 19 patients in the non-pulsatile group (10.9\%), $\mathrm{p}=0.02$.

Consideration of the haemodynamic morbidity figures from both groups of patients suggests a significant haemodynamic superiority in the patients perfused with pulsatile flow. They exhibited a significantly lower intra operative and low outputrelated mortality and had a significantly lower requirement for mechanical and inotropic drug support in the immediate postoperative period.
HAEMATOLOGICAL DATA

The following four parameters were studiedhaemoglobin concentration, haematocrit, and volume of homologous blood transfused; platelet counts—before and 24 hours after operation; incidence of reopening for excessive bleeding; free haemoglobin-absolute levels and calculation of the rise in plasma-free haemoglobin per unit time during the period of perfusion.

\section{Haemoglobin concentration}

In the pulsatile group, the mean preoperative haemoglobin was $14.9 \mathrm{~g} \%$ (range 9.2-18.2) compared with $14.4 \mathrm{~g} \%$ (range $9.5-17.4$ ) in the nonpulsatile group. Twenty-four hours after operation the mean haemoglobin levels were $13.0 \mathrm{~g} \%$ in the pulsatile group and $12.9 \mathrm{~g} \%$ in the non-pulsatile group.

Packed cell volume in the pulsatile group 24 hours after operation was $37.9 \%$ (range 27-46) and in the non-pulsatile group $34.26 \%$ (range 19-45), Homologous blood was transfused in 136 pulsatile patients and in 142 of the non-pulsatile patients. The mean volume transfused in the pulsatile patients was 2.86 units/case compared with 2.99 units/case in the non-pulsatile group. None of these differences is significant.

\section{Platelet counts}

Preoperative platelet count was $246.7 \times 10^{3} \mathrm{~mm}^{-3}$ $( \pm 8.16 \mathrm{SEM})$ in the pulsatile group, and $214.23 \times$ $10^{3} \mathrm{~mm}^{-3}( \pm 6.68 \mathrm{SEM})$ in the non-pulsatile group. Twenty-four hours after operation, platelet counts were $117.92 \times 10^{3} \mathrm{~mm}^{-3}( \pm 9.04$ SEM $)$ in the pulsatile group and $122.84 \times 10^{3} \mathrm{~mm}^{-3}( \pm 8.68 \mathrm{SEM})$ in the non-pulsatile group.

Incidence of reopening for excessive postoperative bleeding

Ten patients in the pulsatile group required reopen- 
ing for excessive postoperative bleeding (5.7\%), compared with 11 patients in the non-pulsatile group $(6.3 \%)$. In the 10 pulsatile patients, none had evidence of bleeding arising from or around the site of aortic bypass cannulation.

\section{Plasma-free haemoglobin levels (table 8)}

Plasma-free haemoglobin levels were determined by the photometric method of Cripps ${ }^{5}$ five minutes before the onset of perfusion (pre-perfusion sample) and five minutes before the end of perfusion (endperfusion sample). In addition to these absolute values, the rise in free haemoglobin during perfusion was calculated and expressed in relation to the duration of perfusion to give the haemolysis index

$$
=\frac{\Delta \text { Plasma free } \mathrm{Hb} \text { during perfusion }(\mathrm{mg} / 100 \mathrm{ml})}{\text { Total perfusion time }(\mathrm{min})}
$$

The pre-perfusion level was $<5 \mathrm{mg} / 100 \mathrm{ml}$ in both groups. In the pulsatile group, the mean level at the end of perfusion was $43.62 \mathrm{mg} / 100 \mathrm{ml}$ (range 18-64), compared to $46.48 \mathrm{mg} / 100 \mathrm{ml}$ (range 22 101 ) in the non-pulsatile group. It should be noted, however, that in none of the pulsatile patients was the end-perfusion free haemoglobin $>70 \mathrm{mg} /$ $100 \mathrm{ml}$, whereas levels up to $101 \mathrm{mg} / 100 \mathrm{ml}$ were found in the non-pulsatile group. The rise in free haemoglobin concentration during perfusion was not significantly different between the groups, nor was the difference in the haemolysis index.

\section{Discussion}

There is general agreement among previous investigators that non-pulsatile perfusion is associated with an increase in peripheral vascular resistance (PVR) during the period of perfusion and that pulsatile perfusion is accompanied by significantly lower PVR levels. ${ }^{6-10}$ The increased clinical awareness of excessive vasoconstriction after cardiopulmonary bypass procedure ${ }^{11-14}$ has been reflected in studies concerned with the pathophysiology and treatment of the elevation in PVR. It is now widely recognised that elevated PVR is a potentially hazardous situation in the early post-bypass period,

Table 8 Haemolysis figures (mean \pm SEM)

\begin{tabular}{|c|c|c|}
\hline & $\begin{array}{l}\text { Pulsatile } \\
\text { group }\end{array}$ & $\begin{array}{l}\text { Non-pulsatile } \\
\text { group }\end{array}$ \\
\hline $\begin{array}{l}\text { Pre-perfusion free } \mathrm{Hb} \\
(\mathrm{mg} / 100 \mathrm{ml})\end{array}$ & $3 \cdot 84 \pm 0 \cdot 13$ & $3.21 \pm 0.11$ \\
\hline $\begin{array}{l}\text { End-perfusion free } \mathrm{Hb} \\
\Delta \text { perfusion free } \mathrm{Hb} \\
\text { Haemolysis Index } \\
(\mathrm{mg} / 100 \mathrm{ml} / \mathrm{min})\end{array}$ & $\begin{array}{c}43.62 \pm 3.64 \\
39.63 \pm 4.21 \\
0.43\end{array}$ & $\begin{array}{r}46.48 \pm 6.31 \\
43.81 \pm 5.63 \\
0.48\end{array}$ \\
\hline
\end{tabular}

since left ventricular work is necessarily increased and sub-endocardial perfusion may be significantly decreased. ${ }^{15-17}$ The use of vasodilator techniques, such as epidural or neuroleptanaesthesia 1819 or drug therapy with sodium nitroprusside,,$^{20-22}$ has been shown to produce a significant improvement in cardiac performance as the elevated PVR falls towards normal levels.

The use of pulsatile perfusion during cardiopulmonary bypass offers the possibility, therefore, of preventing or minimising the potentially harmful elevation in PVR during the perfusion period.

In considering the haemodynamic effects of pulsatile perfusion it is necessary to distinguish between (1) the primary effect of reducing elevated levels of PVR and thus promoting better tissue perfusion, reflected in previous studies demonstrating superior peripheral organ function (eg brain, kidney, pancreas) with pulsatile perfusion, and (2) the secondary effect of improving subsequent left ventricular performance by exposing the left ventricle at the end of perfusion to a significantly lower level of PVR compared with that produced by non-pulsatile perfusion.

It is important to realise that this secondary effect relates to the concept of afterload as an important, even primary, determinant of left ventricular performance $^{15}$ and is separate from any additional direct effect of pulsatile perfusion on the coronary circulation. The results of the present study suggest a significant haemodynamic superiority in the pulsatile group, in terms of both mortality and morbidity.

The essential similarity between the pulsatile and non-pulsatile groups in terms of preoperative characteristics, referral category, and operative protocol accentuates the significantly lower mortality figures in the pulsatile group. Indeed, with a greater number of valve replacement procedures in the pulsatile group one might have anticipated a higher mortality in this group. Detailed consideration of the haemodynamic parameters in both groups gives a clear indication of a fundamental difference in haemodynamic status in the pulsatile group. In particular, there was a significantly lower incidence of low-output-related intraoperative and immediate postoperative deaths when compared with the nonpulsatile group. This clinical finding is in agreement with the results of previous experimental studies, indicating a significant improvement in postperfusion cardiac performance after pulsatile perfusion. ${ }^{23-25}$

The finding of a reduced requirement for circulatory support, with intra-aortic balloon or inotropic drugs, is in keeping with the overall haemodynamic superiority in the pulsatile group. Bregman ${ }^{26}$ has 
reported a similar reduction in the need for postperfusion balloon pumping, and a reduced incidence of perioperative myocardial infarction, in patients perfused with pulsatile flow. Similar findings have been reported by Pappas. ${ }^{27}$

It is likely that the haemodynamic superiority of pulsatile perfusion will be most apparent in patients whose left ventricular function is already severely compromised before operation. In such patients, with severe valvular disease, or ischaemic left ventricular dysfunction, the prevention of excessive elevation in PVR during perfusion may consequently prevent the development of a low-output state in the immediate post-perfusion period.

There is no doubt that certain of the pulsatile systems used in early experimental studies were associated with a high index of haemolysis. ${ }^{28} 29$ The complexity of some early systems and the non-linearity of flow patterns may have caused significant blood cell trauma. More recently, however, haemolysis studies have suggested that pulsatile perfusion does not increase haemolysis to any significant extent, ${ }^{30}$ though Zumbro's group ${ }^{31}$ have reported increased haemolysis using the balloon inflation/deflation PAD system (Datascope).

Extensive haematological studies in the present series and in previous reports have shown that in our experience pulsatile perfusion using the CobeStockert system has not been associated with any significant increase in blood cell trauma or depletion. ${ }^{32}$ The haemolysis figures in the present series have shown that no pulsatile patient had an endperfusion free haemoglobin concentration of $>70 \mathrm{mg} / 100 \mathrm{ml}$. These acceptably low figures have recently been confirmed by Soyer's group in Rouen, also using the Cobe-Stockert system (Soyer, personal communication 1979).

There is an obvious need to determine the haemolysis characteristics of all clinically applicable pulsatile pump systems (particularly those of the intermittent inflation/deflation balloon type) in view of Zumbro's results. ${ }^{31}$ It seems likely, however, that modification of roller pumps to deliver pulsatile flow is not associated with any significant increase in their haemolysis characteristics.

It has been stated by Sanderson ${ }^{33}$ that pulsatile pumps for clinical use should be capable of simulating the ejection phase of cardiac action. This is a counsel of perfection and so far no pump has been developed which will exactly reproduce cardiac action. Despite this fact, many investigators have demonstrated better restoration of normal patterns of metabolism and haemodynamics, using different pulsatile systems, with a considerable variety of flow and pressure output patterns. It may be, therefore, that the body is less rigid in its definition of what constitutes physiologically acceptable pulsatile flow.

It is likely, however, that there are certain features of the pulsatile wave-form which make it "recognisable" to the body as pulsatile perfusion. Where these features are seriously deficient, the disorders associated with non-pulsatile perfusion will result. We share the opinion, expressed by Wright ${ }^{34}$ and by Rainer, ${ }^{35}$ that the rate of rise of the pressure and/or flow profile in the arterial circulation is likely to be at least a major feature of phsyiological significance. Where the upstroke of the pressure curve is "slurred," the physiological effects of pulsatility may be lost.

\section{Conclusions}

The following conclusions may be drawn from the results of the present study concerning the use of pulsatile perfusion during open-heart surgical procedures.

1 The use of pulsatile perfusion with the modified roller-pump system (Cobe-Stockert) has not been associated with any increase in haemolysis, blood cell depletion, or postoperative bleeding problems.

2 Comparison of mortality in a parallel series of pulsatile and non-pulsatile perfusions has shown a significantly lower mortality in the pulsatile group.

3 The significantly lower total mortality was associated with a significantly lower incidence of deaths attributable to low cardiac output during operation or in the post-perfusion period.

4 Requirement for mechanical or drug circulatory support in the post-perfusion period was significantly lower in the pulsatile group.

These results suggest that the routine use of pulsatile perfusion during cardiopulmonary bypass offers significant haemodynamic advantages over conventional non-pulsatile perfusion. Those who, like us, would advocate the adoption of pulsatile perfusion in cardiac surgical practice believe it to be a significant contribution to the overall safety of open-heart surgical procedures.

\section{References}

' Taylor KM, Wright Gillian S, Reid JM et al. Comparative studies of pulsatile and non-pulsatile flow during cardiopulmonary bypass. Part II-The effects on adrenal secretion of cortisol. J Thorac Cardiovasc Surg 1978;75:574-8.

${ }^{2}$ Taylor KM, Wright GS, Bain WH, Caves PK, Beastall GH. Comparative studies of pulsatile and non-pulsatile flow during cardiopulmonary bypass. III-anterior pituitary response to thyrotrophin-releasing-hormone. J Thorac Cardiovasc Surg 1978;75:579-84.

${ }^{3}$ Maxted KJ, Bain WH, Brannan JJ, Taylor KM. Evaluation of the Stockert pump system in the generation of pulsatile flow in extracorporeal circulation. Proc Europ Soc Artif Org (ESAO) 1978;5:226-31. 
4 Taylor KM, Bain WH, Russell Margaret, Brannan JJ, Morton IJ. Peripheral vascular resistance and angiotensin II levels during pulsatile and non-pulsatile cardiopulmonary bypass. Thorax 1979;34:594-8.

${ }^{5}$ Cripps CM. Rapid method for the estimation of plasma haemoglobin levels. J Clin Pathol 1968;21:110-11.

- Dunn J, Kirsh MM, Harness J, Carroll M, Straker J, Sloan H. Haemodynamic, metabolic and hematologic effects of pulsatile cardiopulmonary bypass. $J$ Thorac Cardiovasc Surg 1974;68:138-47.

${ }^{7}$ Landymore RW, Murphy DA, Kinley CE et al. Does pulsatile flow influence the incidence of postoperative hypertension? Ann Thorac Surg 1979;28:261-8.

${ }^{8}$ Mandelbaum I, Burns WH. Pulsatile and non-pulsatile blood flow. JAMA 1965;191:657-62.

- Takeda J. Experimental study of peripheral circulation during extracorporeal circulation with a special reference to a comparison of pulsatile flow with non-pulsatile flow. Arch Jap Chir 1960;29:1407-12.

${ }^{10}$ Giron F, Birtwell WC, Soroff HS, Deterling RA. Haemodynamic effects of pulsatile and non-pulsatile flow. Arch Surg 1966;93:802.

" Estafanous FG, Tarazi RC, Viljoen JF, El Tanil MY. Systemic hypertension following myocardial revascularisation. Am Heart J 1973;85:732-8.

${ }^{12}$ Estafanous FG, Tarazi RC, Buckley S, Taylor PC. Arterial hypertension in immediate post-operative period after valve replacement. Br Heart J 1978;40:718-25.

${ }^{13}$ Estafanous FG. Management of systemic hypertension following myocardial revascularisation. In: Arias A, ed. Recent Progress in Anaesthesiology and Resuscitation. Amsterdam: Excerpta Medica, 1975.

${ }^{14}$ McQueen MJ, Watson ME, Bain WH. Transient systolic hypertension after aortic valve replacement. $\mathrm{Br}$ Heart $J$ 1972;34:227-31.

is Sonnenblick EH, Downing SE. Afterload as a primary determinant of ventricular performance. Am J Physiol 1963;204:604 8.

${ }^{16}$ Roberts AJ, Niarchos AP, Subramanian VA et al. Systemic hypertension associated with coronary artery bypass surgery. J Thorac Cardiovasc Surg 1977;74:846-59.

${ }^{17}$ Gavras H, Kremer D, Brown JJ et al. Angiotensin- and norepinephrine-induced myocardial lesions: experimental and clinical studies in rabbits and man. Am Heart J 1975;89:3216.

${ }^{18}$ Hoar PF, Hickey RF, Ullyot DJ. Systemic hypertension following myocardial revascularisation. J Thorac Cardiovasc Surg 1976;71:859-64.

${ }^{19}$ Stoelting RK, Gibbs PS, Creasser CW, Peterson C. Hemodynamic and ventilatory responses to fentanyl, fentanyl-droperidol, and nitrous oxide in patients with acquired valvular heart disease. Anesthiology 1975;42:31924.
${ }^{20}$ Stinson EB, Holloway EL, Derby GC et al. Control of myocardial performance early after open-heart operations by vasodilator treatment. J Thorac Cardiovasc Surg 1977;73:52330.

${ }^{21}$ Stinson EB, Holloway EL, Derby G et al. Comparative hemodynamic responses to chlorpromazine, nitroprusside, nitroglycerin and trimethaphan immediately after open-heart operations. Circulation 1975;51-52:suppl 1, 26, 33-6.

${ }^{22}$ Kaplan JA, Jones Ellis L. Vasodilator therapy during coronary artery surgery. J Thorac Cardiovasc Surg 1979;77:301-9.

${ }^{23}$ Maddoux G, Pappas G, Jenkins $M$ et al. Effect of pulsatile and non-pulsatile flow during cardiopulmonary bypass on the left ventricular ejection fraction early after aortocoronary bypass surgery. Am J Cardiol 1976;37:1000-6.

${ }^{24}$ Bregman D, Bailin M, Bowman FO et al. A pulsatile assist device (PAD) for use during cardiopulmonary bypass. Ann Thorac Surg 1977;24:574-80.

${ }^{25}$ Bregman D, Bowman FO, Parodi EN et al. An improved method of myocardial protection with pulsation during cardiopulmonary bypass. Circulation 1977; (suppl 11), 56:157-61.

${ }^{26}$ Bregman D. In discussion of paper: Zumbro GL, Shearer G, Fishback ME, Galloway RF. A prospective evaluation of the pulsatile assist device. Ann Thorac Surg 1978;28:269-72.

${ }^{27}$ Pappas G. A simple method of producing pulsatile flow during clinical cardiopulmonary bypass. Ann Thorac Surg 1974;17:405-53.

${ }^{28}$ Wemple RR, Mockros LF, Lewis FJ. Pulmonary function during pulsatile and non-pulsatile right heart bypass. J Thorac Cardiovasc Surg 1969;57:190-202.

${ }^{29}$ Wesolowski SA, Fisher JH, Welch CS. Perfusion of the pulmonary circulation by non-pulsatile flow. Surgery 1953;33:370-5.

${ }^{30}$ Taylor KM. In: Longmore D, ed. Towards safer cardiac surgery. Lancaster: MTP Press, 1981.

${ }^{31}$ Zumbro GL, Shearer G, Fishback ME, Galloway RF. A prospective evaluation of the pulsatile assist device. Ann Thorac Surg 1978;28:269-72.

${ }^{32}$ Taylor KM, Bain WH, Maxted KJ, Hutton MH, McNab WY, Caves PK. Comparative studies of pulsatile and non-pulsatile flow during cardiopulmonary bypass. I-Pulsatile system employed and its haematologic effects. J Thorac Cardiovasc Surg 1978;75:569-73.

${ }^{33}$ Sanderson JM, Morton PG, Tolloczko T, Vennart T, Wright G The Morton-Keele pump: a new hydraulically activated pulsatile pump for use in extracorporeal circulation. Med Biol Eng 1972;11:182-90.

${ }^{34}$ Wright GW. Proceedings of Symposium on Physiological changes during cardiopulmonary bypass. London: Cardiothoracic Institute, 1979.

${ }^{35}$ Rainer WG. Pulsatile versus non-pulsatile pumping. In: Mechanical devices to assist the failing heart. Washington: NAS-NRC Publications, 1966:1283. 